\title{
Bioaccessibility and Gut Metabolism of Free and Melanoidin-Bound Phenolic Compounds From Coffee and Bread
}

\section{Genilton Alves ${ }^{1}$, Leandro Araújo Lobo ${ }^{2}$, Regina Maria Cavalcanti Pilotto Domingues ${ }^{2}$, Mariana Monteiro ${ }^{3}$ and Daniel Perrone ${ }^{1 *}$}

${ }^{1}$ Laboratório de Bioquímica Nutricional e de Alimentos, Biochemistry Department, Chemistry Institute, Federal University of Rio de Janeiro, Rio de Janeiro, Brazil, ${ }^{2}$ Laboratório de Biologia de Anaeróbios, Medical Microbiology Department, Paulo de Goés Microbiology Institute, Federal University of Rio de Janeiro, Rio de Janeiro, Brazil, ${ }^{3}$ Laboratório de Alimentos Funcionais, Nutrition Institute, Federal University of Rio de Janeiro, Rio de Janeiro, Brazil

OPEN ACCESS

Edited by:

Fernando M. Nunes,

University of Trás-os-Montes and Alto

Douro, Portugal

Reviewed by:

José Ángel Rufián Henares,

University of Granada, Spain

Raul Dominguez-Perles,

Consejo Superior de Investigaciones

Científicas (CSIC), Spain

*Correspondence:

Daniel Perrone

danie/perrone@iq.ufri.br

Specialty section:

This article was submitted to

Food Chemistry,

a section of the journal

Frontiers in Nutrition

Received: 12 May 2021

Accepted: 24 June 2021

Published: 26 July 2021

Citation:

Alves G, Lobo LA, Domingues RMCP,

Monteiro M and Perrone D (2021)

Bioaccessibility and Gut Metabolism

of Free and Melanoidin-Bound

Phenolic Compounds From Coffee and Bread. Front. Nutr. 8:708928.

doi: 10.3389/fnut.2021.708928
The aim of this study is to investigate the bioaccessibility and gut metabolism of free and melanoidin-bound phenolic compounds from coffee and bread. Phenolics from coffee were predominantly found in free forms (68\%, mainly chlorogenic acids), whereas those from bread were mostly bound to melanoidins $(61 \%$, mainly ferulic acid). Bioacessibility of coffee total free phenolics slightly decreased during simulated digestion (87, 86, and $82 \%$ after the oral, gastric, and intestinal steps, respectively), with caffeoylquinic acids being isomerized and chlorogenic acids being partially hydrolyzed to the corresponding hydroxycinnamic acids. Bioacessibility of bread total free phenolics decreased during simulated digestion $(91,85$, and $67 \%$ after the oral, gastric, and intestinal steps, respectively), probably related to complexation with the proteins in simulated gastric and intestinal fluids. Upon gut fermentation, the bioaccessibility of total free phenolics from both coffee and bread decreased, mainly after the first $4 \mathrm{~h}$ (56 and $50 \%$, respectively). Caffeic and ferulic acids were the predominant metabolites found during coffee and bread gut fermentation, respectively. Melanoidin-bound phenolics from coffee and bread were progressively released after the gastric and intestinal steps, probably due to hydrolysis caused by the acidic conditions of the stomach and the action of pancreatin from the intestinal fluid. The bioaccessibilities of all phenolics from coffee and bread melanoidins after the gastric and intestinal steps were, on average, 11 and $26 \%$, respectively. During gut fermentation, phenolics bound to both coffee and bread melanoidins were further released by the gut microbiota, whereas those from coffee were also metabolized. This difference could be related to the action of proteases on melanoproteins during gastrointestinal digestion, probably anticipating phenolics release. Nevertheless, bioaccessibilities of melanoidin-bound phenolics reached maximum values after gut fermentation for $24 \mathrm{~h}$ (50\% for coffee and $51 \%$ for bread). In conclusion, the bioaccessibilities of coffee and bread free phenolics during simulated digestion and gut fermentation were remarkably similar, and so were the bioaccessibilities of coffee and bread melanoidin-bound phenolics.

Keywords: chlorogenic acids, ferulic acid, gut fermentation, maillard reaction, melanoproteins, melanosaccharides, simulated digestion 


\section{INTRODUCTION}

In recent years, there has been a growing awareness regarding the beneficial effects of food on health. Current evidence strongly supports that diets rich in plant foods are associated with reduced risk of chronic diseases, including cardiovascular disease and type II diabetes $(1,2)$. These effects are mainly attributed to the presence of various bioactive compounds in these foods, such as phenolic compounds. These compounds are widely diffused in all plant foods including fruits, vegetables, and beverages, such as tea and coffee. Phenolics dietary intake ranges from 377.5 to $1365.1 \mathrm{mg}$ per day, depending on the diet (3). Phenolics in foods occur in free forms (or soluble) or covalently bound to other molecules (or insoluble), especially cell wall components, such as cellulose, hemicellulose, pectin, and structural proteins (4).

In thermally processed foods, several studies have reported that phenolic compounds are involved in the formation of melanoidins, which are generically defined as high molecular weight nitrogenous and brown-colored molecules that contribute to food texture, color, and flavor (5). Melanoidins may be divided into two classes, melanosaccharides (skeletons composed mainly of polysaccharides), present in beverages such as coffee and beer, and melanoproteins (skeletons composed mainly of proteins), present in bakery products $(6,7)$. Although some studies report deleterious effects of melanoidins on health (5), other studies report that the incorporation of phenolic compounds into their structure present health benefits $(8,9)$. Phenolic compounds end up being bound to the backbones of melanoidins, as observed in coffee $(3,10-12)$, bread (3, $13)$, beer $(3,14)$, and many other commonly consumed food $(3,7,15,16)$. It is worth noting that theses melanoidinbound phenolics are not accounted for in the estimates of dietary intake, causing their underestimation by up to $7 \%$ (3). However, the biological relevance of melanoidin-bound phenolics is still poorly understood. To exert their bioactivity, these compounds would have to be released from melanoidins prior to their absorption.

Although clinical studies are considered to be the best approach to investigate the metabolism of phenolic compounds $(17,18)$, in vitro simulated gastrointestinal digestion followed by gut fermentation have been used as a simpler, faster, and less expensive alternative (19-22). Recently, Pérez-Burillo et al. (23) reported the release of phenolics after simulated digestion and gut fermentation of melanoidins from different food sources. Moreover, Liu et al. (9) observed the cellular uptake and trans-enterocyte transport of the phenolics from digested vinegar melanoidins. Together, these studies indicate that melanoidin-bound phenolics have potential to exert biological effects. However, there are no studies in the literature investigating the step-by-step simulated digestion and gut fermentation of melanoidins. Moreover, the bioaccessibility of melanoidin-bound phenolics has never been determined, as well as their comparison to the bioaccessibility of free phenolics from the same food matrix. Thus, the aim of this study is to investigate the bioaccessibility and gut metabolism of free and melanoidin-bound phenolic compounds from coffee and bread.

\section{MATERIALS AND METHODS}

\section{Standards and Chemicals}

Pepsin from porcine stomach mucosa $(250 \mathrm{U} / \mathrm{mg})$, pancreatin $(8 \times$ USP $)$ from porcine pancreas, porcine bile extract, mucin from porcine stomach-type II, albumin, resazurin, cysteine, peptone, yeast extract, pectin, xylan, gum arabic, potato starch, casein, glucose, and inulin were purchased from Sigma-Aldrich Chemical Co. (St. Louis, MO, USA). Phenolic compounds standards (2,4 dihydroxybenzoic, 3,4 dihydroxybenzoic, gallic, benzoic, caffeic, ferulic, $p$-coumaric, salicylic, rosmarinic, and 5-caffeoylquinic acids) were purchased from Sigma-Aldrich Chemical Co. All solvents were HPLC grade from Tedia (Fairfield, OH, USA). HPLC grade water (MilliQ system, Millipore, Bedford, MA, USA) was used throughout the experiments.

\section{Isolation of Free and Melanoidin-Bound Phenolic Compounds From Coffee and Bread}

Coffee brew was prepared at $10 \%(w / v)$ by adding boiling water to commercial ground roasted coffee, agitating for $1 \mathrm{~min}$ using a magnetic stirrer (Corning TM, PC-220) with sufficient speed for complete mixing and filtering through a paper filter (Whatman $\mathrm{n}^{\circ}$. 1). Bread was produced in a domestic bread machine (BK2000B, Breadman, Middleton, WI) by adding in the following order: $245 \mathrm{~mL}$ of water, $15 \mathrm{~mL}$ of extra virgin olive oil, $12 \mathrm{~g}$ of brown sugar, $3 \mathrm{~g}$ of salt $(\mathrm{NaCl}), 30 \mathrm{~g}$ of wheat bran, $270 \mathrm{~g}$ of whole-wheat flour, and $3 \mathrm{~g}$ of dry yeast (Saccharomyces cerevisiae). The bread making process consisted of three stages: mixing (30 $\mathrm{min})$, fermentation (116 $\mathrm{min})$, and baking (47 $\mathrm{min})$. Bread crusts were removed, freeze-dried (Labconco, Kansas City, $\mathrm{MO}$ ), and ground in a mill (A11 Basic, IKAÒ Werke, Staufen, Germany). Extraction of bread crust melanoidins followed the procedure described by Borrelli et al. (24) with modifications. Briefly, $21 \mathrm{~g}$ of freeze-dried bread crust was mixed with $250 \mathrm{~mL}$ of $0.2 \mathrm{M}$ Tris- $\mathrm{HCl}$ buffer ( $\mathrm{pH} 8.0$ ) containing $10 \mathrm{mg} / \mathrm{mL}$ of pancreatin from porcine pancreas. The solution was incubated in an orbital shaker (IKA KS 4000i control, Staufen, Germany) at $37^{\circ} \mathrm{C}$ for $70 \mathrm{~h}$. After centrifugation $\left(3,000 \times \mathrm{g}, 10 \mathrm{~min}, 25^{\circ} \mathrm{C}\right)$, the supernatant was collected.

The coffee brew and the supernatant containing bread melanoidins were subjected to ultrafiltration process using a submerged module system (PAM membranas, Rio de Janeiro, Brazil) with a polyethylenesulfone membrane (average pore size of $10 \mathrm{kDa}$; area of $12 \mathrm{~cm}^{2}$ ) working at a transmembrane pressure of 3 bar. The process was performed at $25^{\circ} \mathrm{C}$, with a continuous agitation. The volume of permeate material (containing free phenolic compounds) was measured daily and an equivalent volume of water was added to the system.

The isolation of coffee free and melanoidin-bound phenolic compounds was carried out in two steps. In the first step, the contents of phenolics in the permeate reduced from 6913.4 $\mathrm{mg} / \mathrm{L}$ (day 1) to $1492.8 \mathrm{mg} / \mathrm{L}$ (day 29). Then, the retentate was freeze-dried, resuspended in water, and subjected to a second ultrafiltration process, in which, after 21 days, the permeate did not present phenolics. The isolation of bread 
free and melanoidin-bound phenolic compounds followed the same procedure, but only one step, which lasted 23 days, was needed for obtaining a permeate with no phenolics present. Both permeate and retentate fractions were freezedried, yielding materials containing free and melanoidin-bound phenolics, respectively.

\section{Analysis of Free and Melanoidin-Bound Phenolic Compounds}

Phenolic compounds analysis in coffee and bread samples followed the methodology described by Perrone, Farah, and Donangelo (11), with modifications. For free phenolics, both permeate and retentate samples $(1 \mathrm{mg} / \mathrm{mL}$ in water) were mixed with solutions of Carrez $\left(0.3 \mathrm{M} \mathrm{K}_{2} \mathrm{Fe}(\mathrm{CN})_{6}\right.$ and $1.0 \mathrm{M}$ zinc acetate) $(1: 100 \mathrm{v} / \mathrm{v})$ for clarification and filtered through a 0.45 $\mu \mathrm{m}$ cellulose ester membrane (Millipore ${ }^{\circledR}$, São Paulo, Brazil) prior to HPLC-DAD analysis. For melanoidin-bound phenolics, retentate samples were subjected to alkaline hydrolysis. Briefly, an aliquot of $750 \mu \mathrm{L}(10 \mathrm{mg} / \mathrm{mL}$ in water $)$ was mixed with $750 \mu \mathrm{L}$ of $2 \mathrm{M} \mathrm{NaOH}$ solution containing $2 \%(w / w)$ ascorbic acid and $20 \mathrm{mM}$ ethylenediaminetetraacetic acid (EDTA). After incubation for $1 \mathrm{~h}$ at $30^{\circ} \mathrm{C}$, hydrolysis was interrupted by adjusting the $\mathrm{pH}$ to 1 with $330 \mu \mathrm{L}$ of $5 \mathrm{M} \mathrm{HCl}$, clarification was performed by adding $20 \mu \mathrm{L}$ of each solutions of Carrez and $130 \mu \mathrm{L}$ of water and the sample was centrifuged prior to HPLC-DAD analysis.

The LC system (Shimadzu, Kyoto, Japan) comprised a LC10ADvp quaternary pump, a CTO-10ASvp column oven, an 8125 manual injector (Rheodyne) with a $20 \mu \mathrm{L}$ loop, and an SPD-M10Avp diode array detector (DAD). Free and melanoidinbound phenolics in coffee were analyzed according to the method described by Farah et al. (25). Chromatographic separations were achieved using a Magic C30 HPLC column (150 $2 \mathrm{~mm}$, $5 \mu \mathrm{m}, 100 \mathrm{~A}$, Michrom Bioresources, Inc., Auburn, CA, USA) maintained at a constant temperature of $40^{\circ} \mathrm{C}$. The LC two-phase mobile system consisted of $0.3 \%$ aqueous formic acid (eluent A) and methanol (eluent $\mathrm{B}$ ). The gradient was programmed with a flow rate of $0.3 \mathrm{~mL} / \mathrm{min}$.

To investigate the content of free and melanoidin-bound phenolics in bread were analyzed according to the method described by Alves and Perrone (13). Chromatographic separations were achieved using a Kromasil ${ }^{\circledR}$ C18 column (5 $\mu \mathrm{m}, 250 \mathrm{~mm}, 4.6 \mathrm{~mm}$ ) maintained at a constant temperature of $40^{\circ} \mathrm{C}$. The LC mobile system consisted of a gradient of water with $0.3 \%$ formic acid (eluent A), methanol (eluent B), and acetonitrile (eluent $\mathrm{C}$, kept at $1 \%$ during the whole run), with a constant flow rate of $1.0 \mathrm{~mL} / \mathrm{min}$.

Phenolic compounds were monitored by DAD between 190 and $370 \mathrm{~nm}$ and identified by comparison of their retention times and UV spectra with those of commercial standards. Quantification was performed by external standardization. The quantification of caffeoylquinic acids (CQA), feruloylquinic acids (FQA), and di-caffeoylquinic acids (diCQA) was performed using the diode array data for the peak area of 5-CQA standard corrected with molar extinction coefficients of the respective CGA, as previously described by Farah et al. (25). Data were acquired by LCMS solution software (Shimadzu Corp., version $2.00,2000)$. Results were expressed as $\mu \mathrm{g} / \mathrm{g}$.

\section{In vitro Gastrointestinal Digestion and Gut Fermentation of Free and Melanoidin-Bound Phenolics}

In vitro gastrointestinal digestion and gut fermentation were performed to mimic human physiological conditions during oral, gastric, small intestinal, and gut steps. The study was conducted following the ethical principles involving human subjects defined in the Declaration of Helsinki and was approved by the research ethics committee of Clementino Fraga Filho Hospital from Federal University of Rio de Janeiro, Brazil (approval number 512.847). The subjects signed an informed consent form. The bioaccessibility of each phenolic compound was calculated as the ratio between the molar concentrations, adjusted to the number of phenolic acid moieties in the molecule (e.g., CQA contains one, whereas di-CQA contains two), in each digestion phase and in the corresponding samples.

\section{In Vitro Gastrointestinal Digestion}

The in vitro gastrointestinal digestion was performed as described by Fernández and Labra (26) and later by de Almeida et al. (19). Three parallel experiments, each reaching a given step of the digestion (oral, gastric, and intestinal) were performed in triplicate. In a glass vial, an aliquot of $0.5 \mathrm{~g}$ of freeze-dried coffee and bread samples were mixed with $3 \mathrm{~mL}$ of human saliva and $2 \mathrm{~mL}$ of water, and the mixture was incubated at $37^{\circ} \mathrm{C}$ in an orbital shaker (Sorvall ST 16R, Thermo Scientific ${ }^{\mathrm{TM}}$ ) for $1 \mathrm{~min}$ at $260 \mathrm{rpm}$. After the oral step, $2.5 \mathrm{~mL}$ of simulated gastric fluid (Supplementary Table 1) was added, and the $\mathrm{pH}$ was adjusted to 2.0 with $5 \mathrm{M} \mathrm{HCl}$. Then, vials were sealed with a silicone septum and atmospheric air was replaced by introducing gaseous nitrogen. Gastric digestion was performed by incubating the mixture at $37^{\circ} \mathrm{C}$ in an orbital shaker for $2 \mathrm{~h}$ at $260 \mathrm{rpm}$. After the gastric step, vials were opened, $2 \mathrm{~mL}$ of simulated intestinal fluid (Supplementary Table 1) were added, and the $\mathrm{pH}$ was adjusted to 6.5 with $1 \mathrm{M} \mathrm{NaHCO}_{3}$. Vials were resealed and nitrogen atmosphere was reestablished. Intestinal digestion was performed by incubating the mixture at $37^{\circ} \mathrm{C}$ in an orbital shaker for $2 \mathrm{~h}$ at $260 \mathrm{rpm}$.

Samples obtained after oral, gastric, and intestinal steps were centrifuged $\left(3,000 \times g, 15 \mathrm{~min}, 25^{\circ} \mathrm{C}\right)$ and the supernatants were passed through Amicon ${ }^{\circledR}$ centrifugal filters with a $10 \mathrm{kDa}$ membrane cut-off (Millipore, Cork, Ireland) prior to HPLCDAD analysis, as described in Section 2.3.

\section{In Vitro Gut Fermentation}

Gut fermentation was performed following the methodology of Inada et al. (20). Fresh feces were donated by a healthy male subject (31 years old, BMI of $24.7 \mathrm{~kg} / \mathrm{m}^{2}$ ) that had regular bowel function, no gastrointestinal diseases, and that did not use antibiotics, dietary supplements, probiotics, prebiotics, and symbiotics in the 3 months prior to the study. For $48 \mathrm{~h}$ prior to feces collection, the subject followed a phenolic-free diet (avoiding fruits and vegetables, legumes, whole cereals, and 
TABLE 1 | Free and melanoidin-bound phenolic compounds in coffee.

\begin{tabular}{|c|c|}
\hline Phenolic compound & Content $(\mu \mathrm{g} / \mathrm{g})^{a}$ \\
\hline \multicolumn{2}{|c|}{ Free phenolics (permeate fraction) } \\
\hline 3-Caffeoylquinic acid & $2,532.2$ \\
\hline 4-Caffeoylquinic acid & $2,014.1$ \\
\hline 5-Caffeoylquinic acid & $2,980.3$ \\
\hline 3-Feruloylquinic acid & 739.3 \\
\hline 4-Feruloylquinic acid & 615.2 \\
\hline 5-Feruloylquinic acid & 944.5 \\
\hline 3,4-Dicaffeoylquinic acid & 456.6 \\
\hline 3,5-Dicaffeoylquinic acid & 339.9 \\
\hline 4,5-Dicaffeoylquinic acid & 507.2 \\
\hline Total free phenolics & $11,129.3$ \\
\hline \multicolumn{2}{|c|}{ Melanoidin-bound phenolics (retentate fraction) } \\
\hline Caffeic acid & $2,312.7$ \\
\hline Ferulic acid & $1,226.4$ \\
\hline 3,4-Dihydroxybenzoic acid & 607.2 \\
\hline Gallic acid & 596.8 \\
\hline Salicylic acid & 535.4 \\
\hline Total melanoidin-bound phenolics & $5,278.5$ \\
\hline
\end{tabular}

${ }^{a}$ Results expressed as mean of two replicates; Coefficient of variation lower than $10 \%$ for all phenolic compounds.

beverages such as coffee, tea, maté, fruit juices, soymilk) and also did not consume yogurts and alcoholic beverages.

In glass test tubes, fecal slurries were diluted with culture growth medium (Supplementary Table 1) at 5\% and mixed with the sample from the last step of the gastrointestinal digestion, which contained all the digested material. Fecal fermentation was performed by incubating the mixture at $37^{\circ} \mathrm{C}$ in an anaerobic chamber (Coylabs, USA) with an atmosphere containing $10 \%$ $\mathrm{H}_{2}, 10 \% \mathrm{CO}_{2}$, and $80 \% \mathrm{~N}_{2}$ under orbital shaking at $50 \mathrm{rpm}$ for 4,24 , and $48 \mathrm{~h}$. Blank experiments in which the digested samples were not added to the fecal slurry were performed to account for the presence of phenolics in the feces samples. In these experiments, no phenolic compounds were detected, indicating that the dietary restriction was adequate to ensure their absence from feces. Parallel experiments, one for each fermentation time, were performed in triplicate. Samples were centrifuged $\left(3,000 \times \mathrm{g}, 15 \mathrm{~min}, 25^{\circ} \mathrm{C}\right)$, the supernatant was sequentially filtered through $0.45 \mu \mathrm{m}$ and $0.22 \mu \mathrm{m}$ cellulose ester membranes (Analitica, São Paulo, Brazil), and were passed through Amicon ${ }^{\circledR}$ centrifugal filters with a $10 \mathrm{kDa}$ membrane cut-off (Millipore, Cork, Ireland) prior to HPLC-DAD analysis, as described in Section "Analysis of free and melanoidin-bound phenolic compounds.”

\section{Statistical Analysis}

Data were expressed as mean \pm standard deviation and processed using Prism for Windows software, version 8.01 (GraphPad Software Inc.). Analysis of variance (one-way ANOVA) followed by Tukey's post hoc test was used to compare the contents of phenolic compounds released among simulated digestion phases
TABLE 2 | Free and melanoidin-bound phenolic compounds in bread.

\begin{tabular}{lc}
\hline Phenolic compound & Content $(\boldsymbol{\mu} \mathbf{g} \mathbf{g})$ \\
\hline \multicolumn{2}{c}{$\quad$ Free phenolics (permeate fraction) } \\
Gallic acid & 448.2 \\
Caffeic acid & 367.7 \\
3,4-Dihydroxybenzoic acid & 315.2 \\
Ferulic acid & 190.7 \\
Rosmarinic acid & 130.2 \\
Total free phenolics & $\mathbf{1 , 4 5 2 . 0}$ \\
& \\
Ferulic acid & $1,397.0$ \\
2,4-Dihydroxybenzoic acid & 605.7 \\
Caffeic acid & 119.9 \\
Gallic acid & 93.4 \\
3,4-Dihydroxybenzoic acid & 78.5 \\
Total melanoidin-bound phenolics & $\mathbf{2 , 2 9 4 . 5}$ \\
\hline
\end{tabular}

${ }^{a}$ Results expressed as mean of two replicates; Coefficient of variation lower than $10 \%$.

(oral, gastric, intestinal, and gut fermentation). Differences were considered significant when $p<0.05$.

\section{RESULTS AND DISCUSSION}

\section{Phenolics From Coffee Were Predominantly Found in Free Forms Whereas Those From Bread Were Mostly Bound to Melanoidins}

Three CQA isomers (3-CQA, 4-CQA, and 5-CQA), three FQA isomers (3-FQA, 4-FQA, and 5-FQA) and three diCQA isomers (3,4-diCQA, 3,5-diCQA, and 4,5-diCQA) were identified among coffee free phenolics (Table 1). 5-CQA was the most abundant CGA (27\%), followed by 3-CQA (23\%) and 4-CQA (18\%), which is in agreement with the literature $(27,28)$. Caffeic, ferulic, 3,4-dihydroxybenzoic, gallic, and salicylic acids were identified among coffee melanoidin-bound phenolics (Table 1). Hydroxycinnamic acids (caffeic and ferulic acids) were the most abundant (67\%), being related to the incorporation of CGA (hydroxycinnamic acid esters) into melanoidins backbone during coffee roasting $(10,12,29)$. Hydroxybenzoic acids represented the remaining phenolics, being 3,4-dihydroxybenzoic and gallic acids the most abundant (69\% in total). These compounds have already been identified in coffee melanoidin samples (29-31). In coffee, total free phenolics contents $(11,129.3 \mu \mathrm{g} / \mathrm{g})$ were higher than that of total melanoidin-bound phenolics $(5,278.5 \mu \mathrm{g} / \mathrm{g})$, as expected from literature data $(10,25)$. One should consider that phenolics are bound to coffee melanoidin through ester bonds, as well as condensed structures and glycosidic bonds. In the present work, we choose to employ only alkaline hydrolysis to analyze coffee melanoidins and, therefore, only phenolic compounds linked through ester bonds were taken into account.

Gallic, caffeic 3,4-dihydroxybenzoic, ferulic, and rosmarinic acids were identified among bread free phenolics. The first three compounds were the most abundant, corresponding to $78 \%$ 


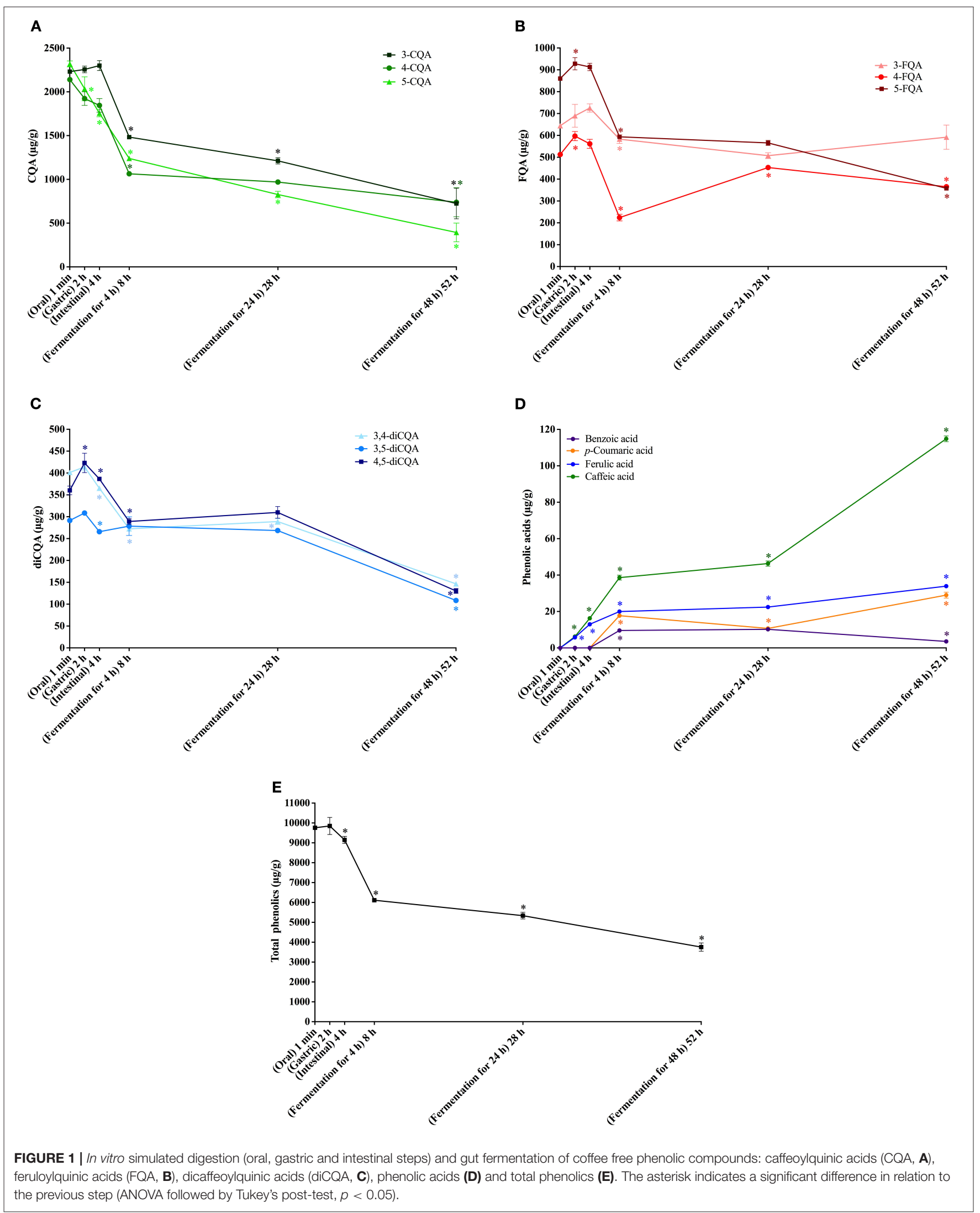


TABLE 3 | Bioaccessibility (\%) of free and melanoidin-bound phenolic compounds from coffee during simulated digestion (oral, gastric, and intestinal steps) and gut fermentation.

\begin{tabular}{|c|c|c|c|c|c|c|c|c|c|c|c|}
\hline \multirow[t]{3}{*}{ Compound } & \multirow[t]{3}{*}{ Oral $\%_{\text {material }}$} & \multicolumn{2}{|c|}{ Gastric } & \multicolumn{2}{|c|}{ Intestinal } & \multicolumn{6}{|c|}{ Gut fermentation } \\
\hline & & \multirow[b]{2}{*}{$\%_{\text {material }}$} & \multirow[b]{2}{*}{$\%_{\text {previous }^{b}}$} & \multirow[b]{2}{*}{$\%_{\text {material }}$} & \multirow[b]{2}{*}{$\%_{\text {previous }}$} & \multicolumn{2}{|c|}{$4 \mathrm{~h}$} & \multicolumn{2}{|c|}{$24 \mathrm{~h}$} & \multicolumn{2}{|c|}{$48 \mathrm{~h}$} \\
\hline & & & & & & $\%_{\text {material }}$ & $\%_{\text {previous }}$ & $\%_{\text {material }}$ & $\%$ previous & $\%_{\text {material }}$ & $\%_{\text {previous }}$ \\
\hline \multicolumn{12}{|l|}{ Free phenolics } \\
\hline 3-Caffeoylquinic acid & 88 & 89 & 101 & 91 & 102 & 59 & 64 & 48 & 82 & 29 & 60 \\
\hline 4-Caffeoylquinic acid & 106 & 95 & 90 & 92 & 96 & 53 & 58 & 48 & 91 & 37 & 76 \\
\hline 5-Caffeoylquinic acid & 78 & 68 & 88 & 59 & 86 & 42 & 71 & 28 & 67 & 13 & 48 \\
\hline 3-Feruloylquinic acid & 87 & 93 & 107 & 98 & 105 & 79 & 80 & 69 & 87 & 80 & 117 \\
\hline 4-Feruloylquinic acid & 83 & 97 & 116 & 91 & 94 & 36 & 40 & 74 & 202 & 59 & 81 \\
\hline 5-Feruloylquinic acid & 91 & 98 & 108 & 97 & 98 & 63 & 65 & 60 & 95 & 38 & 63 \\
\hline 3,4-Dicaffeoylquinic acid & 88 & 91 & 103 & 80 & 88 & 60 & 75 & 63 & 106 & 32 & 51 \\
\hline 3,5-Dicaffeoylquinic acid & 86 & 91 & 106 & 78 & 86 & 82 & 105 & 79 & 96 & 32 & 40 \\
\hline 4,5-Dicaffeoylquinic acid & 71 & 83 & 117 & 76 & 91 & 57 & 75 & 61 & 107 & 26 & 42 \\
\hline Caffeic acid & $-c$ & - & - & - & 261 & - & 237 & - & 120 & - & 248 \\
\hline Ferulic acid & - & - & - & - & 224 & - & 154 & - & 113 & - & 151 \\
\hline$p$-Coumaric acid & - & - & - & - & - & - & - & - & 61 & - & 270 \\
\hline Benzoic acid & - & - & - & - & - & - & - & - & 107 & - & 35 \\
\hline Total phenolics & 87 & 86 & 99 & 82 & 95 & 56 & 68 & 51 & 90 & 35 & 69 \\
\hline \multicolumn{12}{|l|}{ Melanoidin-bound phenolics } \\
\hline Caffeic acid & 0 & 8 & 0 & 14 & 174 & 28 & 205 & 18 & 64 & 10 & 53 \\
\hline Ferulic acid & 0 & 11 & 0 & 18 & 156 & 39 & 222 & 44 & 112 & 17 & 37 \\
\hline 3,4-Dihydroxybenzoic acid & 0 & 16 & 0 & 21 & 131 & 81 & 391 & 148 & 183 & 78 & 53 \\
\hline Gallic acid & 0 & 21 & 0 & 33 & 157 & 107 & 326 & 75 & 70 & 105 & 141 \\
\hline Salicylic acid & 0 & 15 & 0 & 56 & 382 & 28 & 50 & 42 & 149 & 63 & 149 \\
\hline Total phenolics & 0 & 12 & 0 & 23 & 194 & 46 & 199 & 50 & 107 & 38 & 76 \\
\hline
\end{tabular}

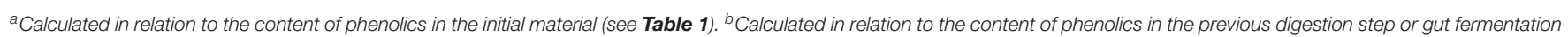
time. ${ }^{c}$ Not applicable.

of free phenolics (Table 2). With the exception of rosmarinic acid, these phenolic compounds identified were linked to bread melanoidins, with the addition of 2,4-dihydroxybenzoic acid. The profile in this sample, however, was very different, with ferulic acid corresponding to $61 \%$ of bound phenolics (Table 2), as widely reported in the literature $(32,33)$. All these phenolics have already been reported in whole-grain wheat flour and bread $(13,19,34,35)$. Contrary to coffee, melanoidin-bound phenolics were more abundant $(2,294.5 \mu \mathrm{g} / \mathrm{g})$ in bread than free phenolics $(1,452.5 \mu \mathrm{g} / \mathrm{g})$, in accordance with previous reports (35-38).

\section{Free Phenolic Compounds From Coffee and Bread Were Extensively Metabolized During Gastrointestinal Digestion and Gut Fermentation \\ Coffee}

All CGA previously found in coffee permeate material (containing free phenolics) were identified after the oral digestion step, that is, three CQA isomers, three FQA isomers, and three di-CQA isomers (Figures 1A-C). On average, free phenolics bioaccessibility after oral digestion was $87 \%$ (Table 3), indicating their almost complete dissolution in saliva. CQA and FQA showed higher bioaccessibilities (on average 89 and $88 \%$, respectively) than diCQA (on average $81 \%$ ), which may be explained by the lower water solubility and higher lipophilicity of the latter class in comparison to the former ones.

No change in coffee total free phenolics bioaccessibility was observed after the gastric digestion step. However, isomerization of CQA isomers was observed (Figure 1A). In comparison to the permeate material, 5-CQA relative content decreased from 40 to $33 \%$ at the same time that 3-CQA and 4-CQA relative contents increased from 34 to $36 \%$ and from 27 to $31 \%$, respectively. In fact, acyl migration is known pathway of CGAs transformation. According to Farrell et al. (39), approximately 2\% of 5-CQA is converted to 3-CQA and 4-CQA after $2 \mathrm{~h}$ of incubation at $\mathrm{pH}$ 7.4. In addition to isomerization, very low quantities of caffeic and ferulic acids were observed (Figure 1D), indicating hydrolysis $(0.13 \%$ of CQA + diCQA to caffeic acid and $0.48 \%$ of FQA to ferulic acid). Even though CGA are said to be stable in artificial and natural gastric fluids (40), Lafay et al. (41) reported traces of caffeic acid in the stomach of rats fed with a diet supplemented with CGA. Considering that gastric juice do not possess esterases capable of hydrolyzing CGA to release caffeic and ferulic acids (42), we can suppose that in the stomach, CGA would be hydrolyzed to release the corresponding hydroxycinnamic acids 
due to the acidic conditions. After the intestinal step, coffee free phenolics bioaccessibility slightly decreased (Figure 1E), reaching $82 \%$ (Table 2). Moreover, isomerization of 5-CQA to 3-CQA continued to occur and CGA hydrolysis increased, with $0.34 \%$ of the sum of CQA and diCQA being converted to caffeic acid and $1.07 \%$ of FQA being hydrolyzed to ferulic acid. Both isomerization and hydrolysis of CGA in intestinal fluids have been reported in the literature (40).

After simulation of gastrointestinal digestion, coffee permeate material was submitted to gut fermentation. During $48 \mathrm{~h}$ of fermentation, a decrease in total phenolic compounds bioaccessibility was observed (Figure 1E). The most expressive reduction was observed after the first $4 \mathrm{~h}$, reaching 56\%, followed by reductions after $24 \mathrm{~h}(51 \%)$ and $48 \mathrm{~h}(35 \%)$ (Table 2). Caffeic acid was the metabolite found at the highest concentrations throughout the fermentation process. In fact, during gut fermentation, CGA continue to be hydrolyzed, especially toward the end of the $48 \mathrm{~h}$, when $2.6 \%$ of CGA, on average, were converted to their corresponding hydroxycinnamic acids (Figure 1D). FQA showed a lower decrease in their bioaccessibility (from $96 \%$ at the intestinal step to $57 \%$ after $48 \mathrm{~h}$ of gut fermentation) in comparison to CQA and diCQA (from 78 to $28 \%$ ), suggesting that the former class was less metabolized than the latter ones. The presence of benzoic acid may be explained by aromatization of quinic acid (43) or hydrolysis and $\beta$-oxidation of caffeic and ferulic acids (44).

Even though only $3.6 \%$ of free phenolics present in coffee permeate material were quantified as metabolites after gut fermentation for $48 \mathrm{~h}$, the intense decrease in total CGA suggests their extensive metabolization, since they are known to be stable at these $\mathrm{pH}$ and temperature conditions. Even though Ludwig et al. (45) reported that dihydrocaffeic acid was the major metabolite of CGA formed during gut fermentation, we did not found this compound in our experiments. Also, differently from our results, these authors reported that caffeic and ferulic acids were initial degradation products, with a transient appearance and maximum quantities after $1 \mathrm{~h}$ of fermentation. These differences may result from the rate and extent of the degradation, which show a clear influence of amount and composition of the gut microbiota (46). In fact, Breynaert et al. (47) observed different outcomes when CGA were incubated for $6 \mathrm{~h}$ with two concentration of gut microorganisms. At the higher concentration (108 CFU/mL), CGA were completely metabolized, yielding mainly dihydrocaffeic acid. On the other hand, at a lower concentration (105 CFU/mL), CGA were still observed, and the main metabolite was caffeic acid. Therefore, we can suppose that the concentration of microorganisms in our fecal slurry was probably not sufficient to catabolize all CGA present.

\section{Bread}

All phenolic compounds previously found in bread permeate material (containing free phenolics) were identified after the oral digestion step, that is three hydroxycinnamic acid derivatives (caffeic, ferulic, and rosmarinic acids) and two hydroxybenzoic acid derivatives (gallic and 3,4-dihydroxybenzoic acids) (Figure 2A). On an average, free phenolics bioaccessibility

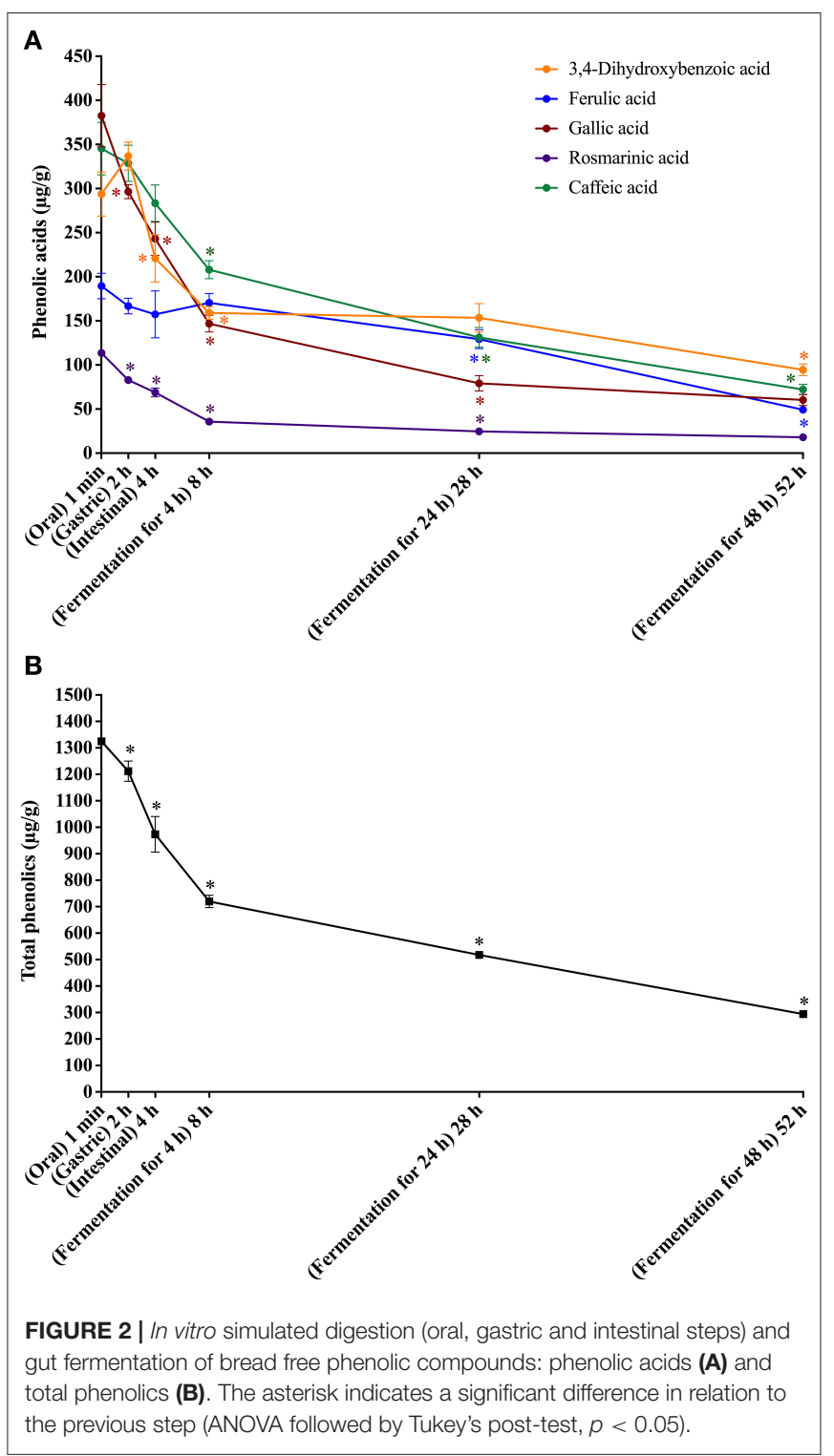

after oral digestion was 91\% (Table 4), indicating their almost complete dissolution in saliva related to their high solubility in water.

After the gastric digestion step, the bioaccessibility of bread total free phenolics decreased (Figure 2B), reaching $85 \%$ (Table 4), as a consequence of the reduction in the contents of gallic and rosmarinic acids (Figure 2A). The free phenolic compounds may form low-solubility complexes with proteins (34), such as those from the simulated gastric juice. These complexes cannot pass through the filtration membrane used in the present study $(17,48)$, possibly explaining the observed reduction in bioaccessibility. This effect could not be observed in the experiments with coffee probably due to their much higher free phenolics content $(11.1 \mathrm{mg} / \mathrm{g})$ in comparison to bread $(1.4 \mathrm{mg} / \mathrm{g})$. After the intestinal step, bread free phenolics bioaccessibility continued to decrease (Figure 2B), reaching 67\% 
TABLE 4 | Bioaccessibility (\%) of free and melanoidin-bound phenolic compounds from bread during simulated digestion (oral, gastric, and intestinal steps) and gut fermentation.

\begin{tabular}{|c|c|c|c|c|c|c|c|c|c|c|c|}
\hline \multirow[t]{3}{*}{ Compound } & \multirow[t]{3}{*}{ Oral $\%_{\text {material }}{ }^{\mathrm{a}}$} & \multicolumn{2}{|c|}{ Gastric } & \multicolumn{2}{|c|}{ Intestinal } & \multicolumn{6}{|c|}{ Gut fermentation } \\
\hline & & \multirow[b]{2}{*}{$\%_{\text {material }}$} & \multirow[b]{2}{*}{$\%_{\text {previous }^{b}}$} & \multirow[b]{2}{*}{$\%_{\text {material }}$} & \multirow[b]{2}{*}{$\%$ previous } & \multicolumn{2}{|c|}{$4 \mathrm{~h}$} & \multicolumn{2}{|c|}{$24 \mathrm{~h}$} & \multicolumn{2}{|c|}{$48 \mathrm{~h}$} \\
\hline & & & & & & $\%_{\text {material }}$ & $\%$ previous & $\%_{\text {material }}$ & $\%$ previous & $\%_{\text {material }}$ & $\%_{\text {previous }}$ \\
\hline \multicolumn{12}{|l|}{ Free phenolics } \\
\hline Gallic acid & 85 & 66 & 78 & 54 & 82 & 33 & 60 & 18 & 54 & 13 & 76 \\
\hline Caffeic acid & 94 & 89 & 95 & 77 & 86 & 57 & 73 & 36 & 63 & 20 & 55 \\
\hline 3,4-Dihydroxybenzoic acid & 93 & 107 & 115 & 70 & 66 & 50 & 72 & 49 & 97 & 30 & 62 \\
\hline Ferulic acid & 96 & 87 & 91 & 83 & 94 & 89 & 108 & 68 & 76 & 26 & 38 \\
\hline Rosmarinic acid & 87 & 64 & 73 & 53 & 83 & 27 & 52 & 19 & 69 & 14 & 73 \\
\hline Total phenolics & 91 & 85 & 93 & 67 & 79 & 50 & 74 & 36 & 73 & 21 & 57 \\
\hline \multicolumn{12}{|l|}{ Melanoidin-bound phenolics } \\
\hline Ferulic acid & 0 & 9 & 0 & 36 & 396 & 36 & 103 & 55 & 152 & 44 & 79 \\
\hline 2,4-Dihydroxybenzoic acid & 0 & 7 & 0 & 17 & 234 & 19 & 110 & 42 & 219 & 57 & 135 \\
\hline Caffeic acid & 0 & 25 & 0 & 50 & 196 & 59 & 119 & 86 & 145 & 51 & 59 \\
\hline Gallic acid & 0 & 15 & 0 & 29 & 192 & 45 & 156 & 26 & 59 & 70 & 265 \\
\hline 3,4-Dihydroxybenzoic acid & 0 & 9 & 0 & 21 & 233 & 17 & 83 & 46 & 265 & 55 & 118 \\
\hline Total phenolics & 0 & 10 & 0 & 30 & 310 & 32 & 107 & 51 & 161 & 50 & 97 \\
\hline
\end{tabular}

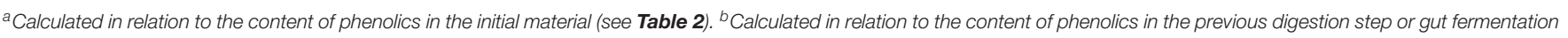
time. ${ }^{c}$ Not applicable.

(Table 4). This was caused by decrease in the contents of gallic, caffeic, and 3,4-dihydroxybenzoic acids, which were probably related to further complexation with the proteins present in the simulated intestinal fluid.

Upon gut fermentation, total phenolic compounds bioaccessibility progressively reduced (Figure 2B). As observed for coffee free phenolics, the most expressive reduction occurred after $4 \mathrm{~h}$, reaching $50 \%$, decreasing to 36 and $21 \%$ after 24 and $48 \mathrm{~h}$, respectively (Table 4). Considering individual phenolics, the contents of all compounds decreased after $4 \mathrm{~h}$ of gut fermentation, with the exception of ferulic acid, which did not change. In the following times, the decreases were less pronounced, and it is worth noting that only 3,4dihydroxybenzoic acid contents remained unaltered after $24 \mathrm{~h}$ of fermentation. This result may be explained by a possible conversion of gallic acid (3,4,5-trihydroxybenzoic acid) through the loss of hydroxyl in its structure (49). Together, the results of this study show that bread free phenolics were extensively metabolized during simulated digestion and gut fermentation, as also described above for coffee free phenolics.

\section{Bound Phenolic Compounds From Coffee and Bread Were Released From Melanoidins and Metabolized During Gastrointestinal Digestion and Gut Fermentation}

Different from that observed after the oral digestion step of free phenolics, no phenolic compounds were observed after the oral digestion step of coffee and bread retentates (Figures 3A, 4A). This is probably related to the very short incubation time (1 min) and to the neutral $\mathrm{pH}$, which were insufficient to release phenolics from the melanoidins skeleton. All phenolics previously found in coffee and bread retentate material (containing melanoidin-bound phenolics) were identified after the gastric digestion step: two hydroxycinnamic acid derivatives (caffeic and ferulic acids) and three hydroxybenzoic acid derivatives (3,4-dihydroxybenzoic, gallic, and salicylic acids) in coffee; two hydroxycinnamic acid derivatives (caffeic and ferulic acids) and three hydroxybenzoic acid derivatives (2,4-dihydroxybenzoic, 3,4-dihydroxybenzoic, and gallic acids) in bread. In comparison to the retentate materials, the bioaccessibility of all phenolics from coffee and bread melanoidins progressively increased (Figures 3B, 4B) after the gastric (12 and 10\%, on average, respectively) and intestinal steps (23 and 30\%, on average, respectively) (Tables 3, 4). This was due to the release of phenolics, which may be associated to the acidic conditions of the stomach, as well as the action of pancreatin in the intestinal fluid, which would hydrolyze the ester bonds that most commonly link phenolics to melanoidins (50). In addition, proteases in the gastric and intestinal fluids could act on melanoproteins, enhancing the action of the aforementioned esterases. This would possibly explain the higher phenolics release from bread in comparison to coffee, since the former is known to contain melanoproteins (51) and the latter melanosaccharides (7). In terms of individual compounds and comparing the intestinal with the gastric step, it is worth noting that salicylic acid was the phenolic with the most expressive release from coffee melanoidins, whereas the same can be said on ferulic acid from bread melanoidins (Figures 3A, 4A).

Upon gut fermentation for $4 \mathrm{~h}$, total phenolic compounds contents from coffee doubled (Figure 3A), indicating an 
extensive release from melanoidins due to the action of microbiota, leading to a bioaccessibility of $46 \%$ (Table 3). On the other hand, total phenolic compounds contents from bread did not change during the same period (Figure 3B), leading to a bioaccessibility of $32 \%$ (Table 4 ). This difference could be related to the action of proteases during gastrointestinal digestion, as previously discussed, which probably anticipated phenolics release. After $24 \mathrm{~h}$ of gut fermentation, phenolic compounds bioaccessibility of coffee bound-phenolics did not significantly change (50\%) and decreased thereafter (38\%) (Table 3). In contrast, phenolic compounds bioaccessibility of bread boundphenolics increased after $24 \mathrm{~h}$ of gut fermentation (51\%) and did not significantly change (50\%) after $48 \mathrm{~h}$ (Table 4). These results indicate that while phenolics bound to both coffee and bread melanoidins were released by the gut microbiota, those from coffee were further metabolized (Figure 5).

Recently, Pérez-Burillo et al. (23) submitted melanoidins from different food sources, including coffee and bread, to simulated digestion and gut fermentation. According to these authors, gut microbes were able to release some phenolics initially linked to the melanoidin backbone. However, this study was the first one, to the best of our knowledge, to investigate the stepby-step effect of simulated digestion and gut fermentation on melanoidins and to determine the bioaccessibility of melanoidinbound phenolics. The amounts of phenolics released from coffee and bread melanoidins were much higher in our study, respectively $2,525.9 \mu \mathrm{g} / \mathrm{g}$ and $1,191.9 \mu \mathrm{g} / \mathrm{g}$ after gut fermentation for $24 \mathrm{~h}$, than those reported by Pérez-Burillo et al. (23), of $48.8 \mu \mathrm{g} / \mathrm{g}$ and $2.2 \mu \mathrm{g} / \mathrm{g}$ after gut fermentation for $20 \mathrm{~h}$. These differences could be related to the different media used in the studies. While we carried out gut fermentation experiments with a nutrient-rich medium, considered to be more representative of the carbon sources physiologically available to microbiota, those authors used a nutrient-poor medium, which could artificially stimulate the use of phenolic compounds as sources of carbon skeletons. Moreover, the medium of this study is more appropriate to maintain the taxonomic diversity of the feces microbiota, as nutrient-poor media are known to impede the survival of many species of bacteria (52). Pérez-Burillo et al. (23) also discussed that coffee melanoidins released more phenolics than bread melanoidins, which was similar to the one observed in this study. However, when the amount of phenolics initially linked to melanoidins backbone is considered, we observed that the bioaccessibility of phenolic compounds from coffee and bread melanoidins was similar (50\% and $51 \%$ after $24 \mathrm{~h}$ of gut fermentation, respectively) (Figure 5).

Phenolic compounds and their metabolites interact with the gut microbiota, exerting effects on human health. Many studies show that there is a bi-directional interaction between dietary polyphenols and the gut microbiota, being mutually beneficial (52). In the particular case of melanoidins, their digestion caused an increase in the production of short-chain fatty acids and favored the growth of beneficial microorganisms (23), possibly acting as prebiotics. In fact, many authors consider that melanoidins have characteristics of dietary fibers, being highly metabolized by the gut microbiota (53-55). In addition

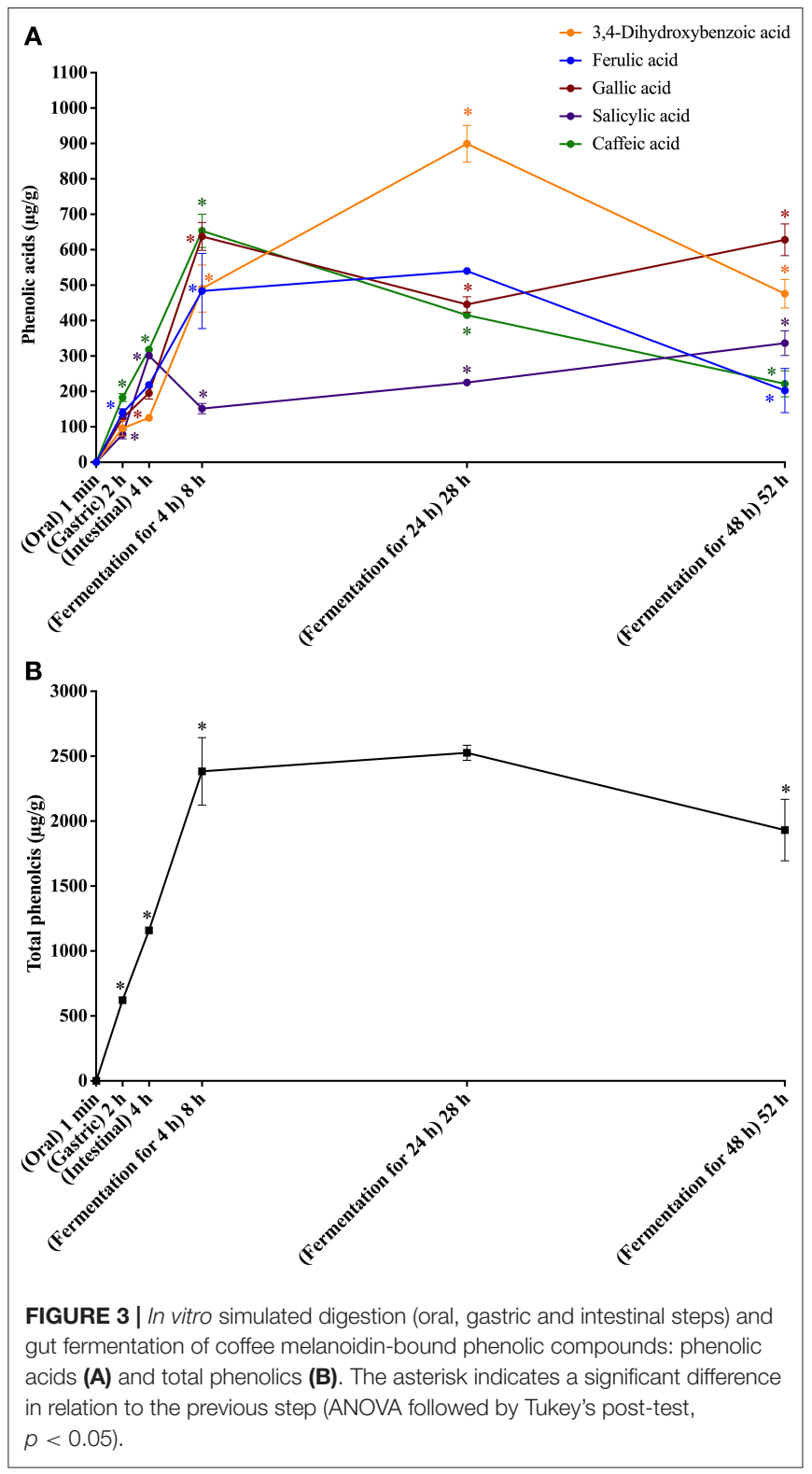

to these in situ effects, phenolics released from melanoidins could be potentially absorbed in the gut and exert several systemic biological activities (52). In this context, it is worth mentioning that considering that the daily intake of coffee melanoidins leads to the intake of $19.5 \mathrm{mg}$ of phenolics (3), one could argue that these macromolecules would significantly contribute to the health effects of coffee consumption. Finally, we can hypothesize that our results regarding the release of bound phenolics could be extrapolated, at least in part, to nonthermally processed plant foods. In cereal-based foods, most phenolic compounds are found in the insoluble bound form, while in fruits and vegetables their content is lower, but still considerable $(56,57)$. If this hypothesis proves true, it would be undeniable that insoluble phenolics play a key role in the 


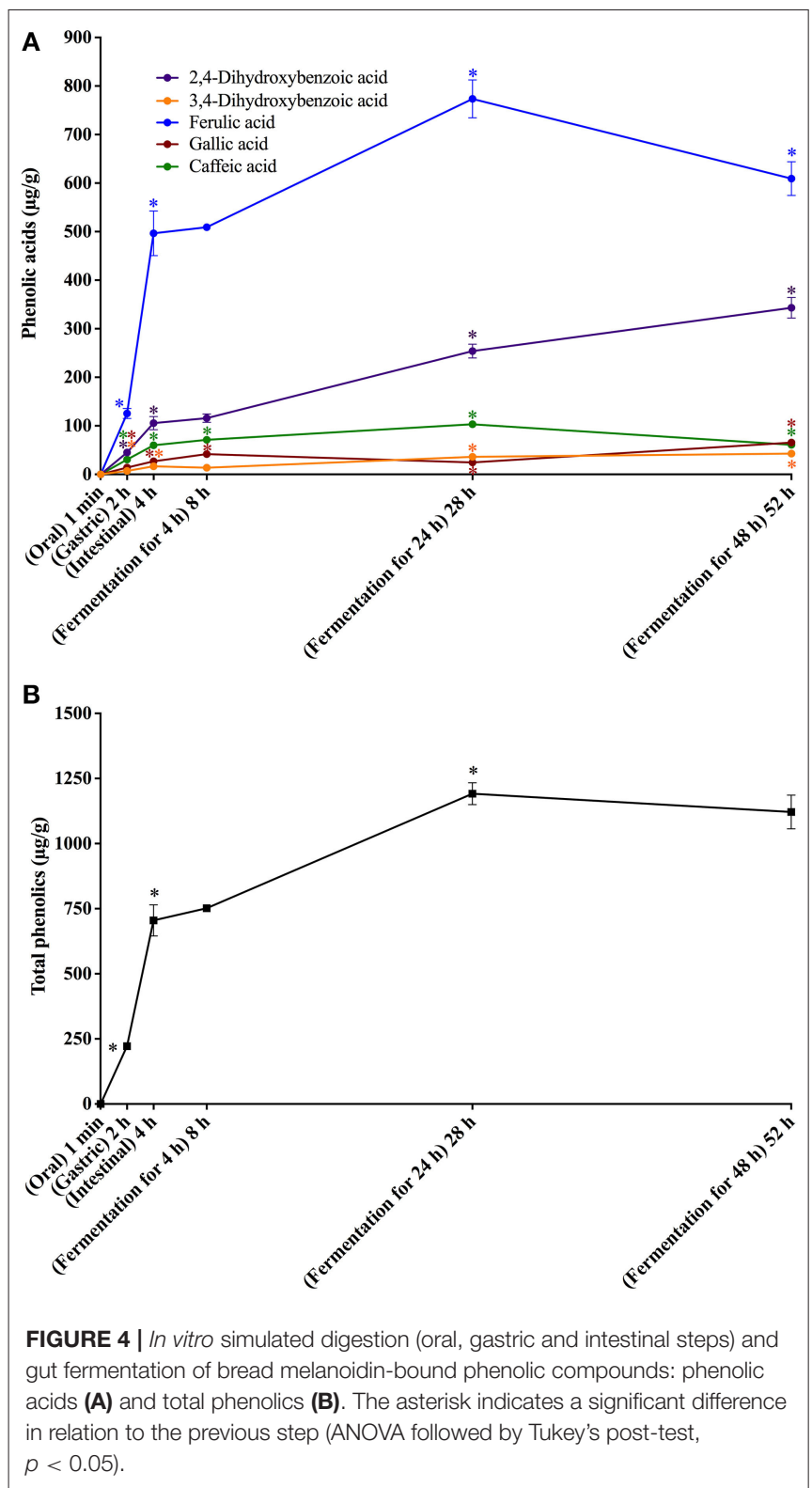

health effects associated with diets rich in fruits, vegetables, and especially whole grains.

\section{CONCLUSIONS}

Phenolics from coffee were predominantly found in free forms, whereas those from bread were mostly bound to melanoidins. During simulated digestion of coffee free phenolics, CQA isomerized and CGA hydrolyzed forming the corresponding hydroxycinnamic acids. Bioacessibility of bread total free phenolics decreased during simulated digestion, probably related to complexation with the proteins in simulated gastric and intestinal fluids. Upon gut fermentation, the bioaccessibility of total phenolic compounds from both coffee and bread decreased,

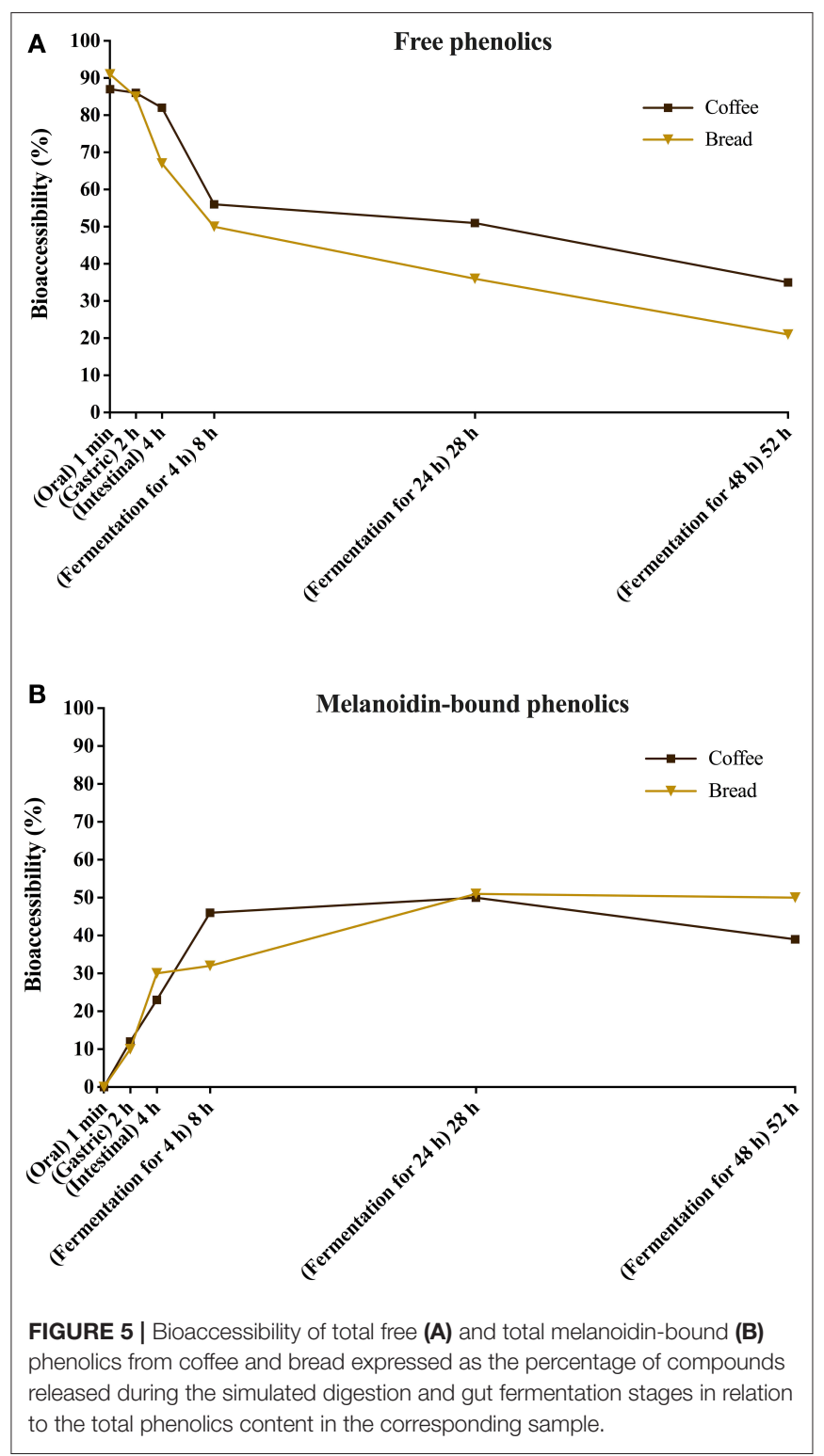

mainly after the first $4 \mathrm{~h}$. Caffeic and ferulic acids were the predominant metabolites found during coffee and bread gut fermentation, respectively. Melanoidin-bound phenolics from coffee and bread were progressively released after the gastric and intestinal steps, probably due to hydrolysis caused by the acidic conditions of the stomach and the action of pancreatin from the intestinal fluid. During gut fermentation, phenolics bound to both coffee and bread melanoidins were further released by the gut microbiota, whereas those from coffee were also metabolized. This difference could be related to the action of proteases on melanoproteins during gastrointestinal digestion, probably anticipating phenolics release. Finally, the bioaccessibilities of coffee and bread free phenolics during simulated digestion and gut fermentation were remarkably similar, and so were the bioaccessibilities of coffee and bread melanoidin-bound phenolics. Further analyses should be done in the future using 
high-resolution mass spectrometry to describe in more detail the gut metabolites from phenolics released from melanoidins.

\section{DATA AVAILABILITY STATEMENT}

The raw data supporting the conclusions of this article will be made available by the authors, without undue reservation.

\section{ETHICS STATEMENT}

The studies involving human participants were reviewed and approved by Research ethics committee of Clementino Fraga Filho Hospital from Federal University of Rio de Janeiro, Brazil (approval number 512.847). The patients/participants provided their written informed consent to participate in this study.

\section{AUTHOR CONTRIBUTIONS}

GA: Methodology, validation, formal analysis, investigation, data curation, writing-original draft, visualization. LL and RD: Resources, writing-review and editing.

\section{REFERENCES}

1. Bondonno NP, Dalgaard F, Kyrø C, Murray K, Bondonno CP, Lewis JR, et al. In the Danish Diet Cancer and Health Cohort. Nat Commun. (2019) 1-10. doi: 10.1038/s41467-019-11622-x

2. Liu RH. Dietary bioactive compounds and their health implications. J Food Sci. (2013) 78:A18-25. doi: 10.1111/1750-3841.12101

3. Alves G, Xavier P, Limoeiro R, Perrone D. Contribution of melanoidins from heat-processed foods to the phenolic compound intake and antioxidant capacity of the Brazilian diet. J Food Sci Technol. (2020) 57:3119-31. doi: 10.1007/s13197-020-04346-0

4. Shahidi F, Yeo J. Insoluble-Bound Phenolics in Food. Molecules. (2016) 21:1216 doi: $10.3390 /$ molecules 21091216

5. Echavarría AP, Pagán J, Ibarz A. Melanoidins formed by maillard reaction in food and their biological activity. Food Eng Rev. (2012) 4:203-23. doi: 10.1007/s12393-012-9057-9

6. Helou C, Jacolot P, Niquet-Léridon C, Gadonna-Widehem P, Tessier FJ. Maillard reaction products in bread: A novel semi-quantitative method for evaluating melanoidins in bread. Food Chem. (2016) 190:904-11. doi: 10.1016/j.foodchem.2015.06.032

7. Pastoriza S, Rufián-Henares JA. Contribution of melanoidins to the antioxidant capacity of the Spanish diet. Food Chem. (2014) 164:438-45. doi: 10.1016/j.foodchem.2014.04.118

8. Mesías M, Delgado-Andrade C. Melanoidins as a potential functional food ingredient. Curr Opin Food Sci. (2017) 14:37-42. doi: 10.1016/j.cofs.2017.01.007

9. Liu J, Gan J, Nirasawa S, Zhou Y, Xu J, Zhu S, et al. Cellular uptake and trans-enterocyte transport of phenolics bound to vinegar melanoidins. J Funct Foods. (2017) 37:632-40. doi: 10.1016/j.jff.2017. 08.009

10. Moreira ASP, Nunes FM, Simões C, Maciel E, Domingues P, Domingues MRM, et al. Transglycosylation reactions, a main mechanism of phenolics incorporation in coffee melanoidins: Inhibition by Maillard reaction. Food Chem. (2017) 227:422-31. doi: 10.1016/j.foodchem.2017. 01.107

11. Perrone D, Farah A, Donangelo CM. Influence of coffee roasting on the incorporation of phenolic compounds into melanoidins and their relationship with antioxidant activity of the brew. J Agric Food Chem. (2012) 60:4265-75. doi: $10.1021 /$ jf205388x
MM: Writing-review and editing, visualization. DP: Conceptualization, data curation, writing-review \& editing, visualization, supervision, project administration, funding. All authors contributed to the article and approved the submitted version.

\section{FUNDING}

The financial support of Fundação Carlos Chagas Filho de Amparo à Pesquisa do Estado do Rio de Janeiro (FAPERJ; E-26/203.276/2016, E-26/010.000266/2017, E26/202.708/2018, E-26/210.151/2018, E-26/010.101004/2018, and E-26/202.694/2019) is greatly acknowledged. This study was financed in part by the Coordenação de Aperfeiçoamento de Pessoal de Nível Superior - Brasil (CAPES)-Finance Code 001.

\section{SUPPLEMENTARY MATERIAL}

The Supplementary Material for this article can be found online at: https://www.frontiersin.org/articles/10.3389/fnut.2021. 708928/full\#supplementary-material
12. Bekedam EK, Schols HA, Van Boekel MAJS, Smit G. Incorporation of chlorogenic acids in coffee brew melanoidins. J Agric Food Chem. (2008) 56:2055-63. doi: 10.1021/jf073157k

13. Alves G, Perrone D. Breads enriched with guava flour as a tool for studying the incorporation of phenolic compounds in bread melanoidins. Food Chem. (2015) 185:65-74. doi: 10.1016/j.foodchem.2015.03.110

14. Moura-Nunes N, Brito TC, Fonseca ND da, de Aguiar PF, Monteiro M, Perrone D, et al. Phenolic compounds of Brazilian beers from different types and styles and application of chemometrics for modeling antioxidant capacity. Food Chem. (2016) 199:105-13. doi: 10.1016/j.foodchem.2015.11.133

15. Oracz J, Nebesny E, Zyzelewicz D. Identification and quantification of free and bound phenolic compounds contained in the high-molecular weight melanoidin fractions derived from two different types of cocoa beans by UHPLC-DAD-ESI-HR-MSn. Food Res Int. (2018) 115:135-149. doi: 10.1016/j.foodres.2018.08.028

16. Fogliano V, Morales FJ. Estimation of dietary intake of melanoidins from coffee and bread. Food Funct. (2011) 2:117-23. doi: 10.1039/c0fo00156b

17. Alminger M, Aura AM, Bohn T, Dufour C, El SN, Gomes A, et al. In vitro models for studying secondary plant metabolite digestion and bioaccessibility. Compr Rev Food Sci Food Saf. (2014) 13:413-36. doi: 10.1111/1541-4337.12081

18. Minekus M, Alminger M, Alvito P, Ballance S, Bohn T, Bourlieu $\mathrm{C}$, et al. A standardised static in vitro digestion method suitable for food - an international consensus. Food Funct. (2014) 5:1113-24. doi: 10.1039/C3FO60702J

19. de Almeida SS, da Costa GBM, Barreto MS, Freire DMG, Lobo LA, Domingues RMCP, et al. Bioaccessibility and gut metabolism of phenolic compounds of breads added with green coffee infusion and enzymatically bioprocessed. Food Chem. (2020) 333:127473. doi: 10.1016/j.foodchem.2020.127473

20. Inada KOP, Silva TBR, Lobo LA, Domingues RMCP, Perrone D, Monteiro M. Bioaccessibility of phenolic compounds of jaboticaba (Plinia jaboticaba) peel and seed after simulated gastrointestinal digestion and gut microbiota fermentation. J Funct Foods. (2020) 67:103851. doi: 10.1016/j.jff.2020.103851

21. Williamson G, Clifford MN. Role of the small intestine, colon and microbiota in determining the metabolic fate of polyphenols. Biochem Pharmacol. (2017) 139:24-39. doi: 10.1016/j.bcp.2017.03.012

22. Campos-Vega R, Vázquez-Sánchez K, López-Barrera D, Loarca-Piña G, Mendoza-Díaz S. Oomah BD. Simulated gastrointestinal digestion 
and in vitro colonic fermentation of spent coffee (Coffea arabica L): Bioaccessibility and intestinal permeability. Food Res Int. (2015) 77:156-61. doi: 10.1016/j.foodres.2015.07.024

23. Pérez-Burillo S, Rajakaruna S, Pastoriza S, Paliy O, Ángel Rufián-Henares J. Bioactivity of food melanoidins is mediated by gut microbiota. Food Chem. (2020) 316:126309. doi: 10.1016/j.foodchem.2020.126309

24. Borrelli RC, Mennella C, Barba F, Russo M, Russo GL, Krome K, et al. Characterization of coloured compounds obtained by enzymatic extraction of bakery products. Food Chem Toxicol. (2003) 41:1367-74. doi: 10.1016/S0278-6915(03)00140-6

25. Farah A, De Paulis T, Trugo LC, Martin PR. Effect of roasting on the formation of chlorogenic acid lactones in coffee. J Agric Food Chem. (2005) 53:1505-13. doi: 10.1021/jf048701t

26. Fernández K, Labra J. Simulated digestion of proanthocyanidins in grape skin and seed extracts and the effects of digestion on the angiotensin Iconverting enzyme (ACE) inhibitory activity. Food Chem. (2013) 139:196202. doi: 10.1016/j.foodchem.2013.01.021

27. Fujioka K, Shibamoto T. Chlorogenic acid and caffeine contents in various commercial brewed coffees. Food Chem. (2008) 106:217-21. doi: 10.1016/j.foodchem.2007.05.091

28. Farah A, Donangelo CM. Phenolic compounds in coffee. Brazilian J Plant Physiol. (2006) 18:23-36. doi: 10.1590/S1677-04202006000100003

29. Coelho C, Ribeiro M, Cruz ACS, Domingues MRM, Coimbra MA, Bunzel M, et al. Nature of phenolic compounds in coffee melanoidins. J Agric Food Chem. (2014) 62:7843-53. doi: 10.1021/jf501510d

30. Khajeh M, Fard S, Bohlooli M, Khatibi MGA. Extraction of caffeine and gallic acid from coffee by electrokinetic methods coupled with a hollow-fiber membrane. J Food Process. (2017) 1-5. doi: 10.1111/jfpe. 12565

31. Dogasaki C, Shindo T, Furuhata K, Fukuyama M. Identification of chemical structure of antibacterial components against legionella pneumophila in a coffee beverage. Yakugaku Zasshi. (2002) 122:487-94. doi: 10.1248/yakushi.122.487

32. Bresciani L, Scazzina F, Leonardi R. Dall'Aglio E, Newell M, Dall'Asta M, Melegari C, et al. Bioavailability and metabolism of phenolic compounds from wholegrain wheat and aleurone-rich wheat bread. Mol Nutr Food Res. (2016) 60:2343-54. doi: 10.1002/mnfr.201600238

33. Yu L, Nanguet A-L, Beta T. Comparison of Antioxidant Properties of Refined and Whole Wheat Flour and Bread. Antioxidants. (2013) 2:370-83. doi: 10.3390/antiox2040370

34. Angelino D, Cossu M, Marti A, Zanoletti M, Chiavaroli L, Brighenti F, et al. Bioaccessibility and bioavailability of phenolic compounds in bread: A review. Food Funct. (2017) 8:2368-93. doi: 10.1039/C7FO00574A

35. Vitaglione P, Napolitano A, Fogliano V. Cereal dietary fibre: a natural functional ingredient to deliver phenolic compounds into the gut. Trends Food Sci Technol. (2008) 19:451-63. doi: 10.1016/j.tifs.2008.02.005

36. Laddomada B, Caretto S, Mita G. Wheat bran phenolic acids: Bioavailability and stability in whole wheat-based foods. Molecules. (2015) 20:15666-85. doi: 10.3390/molecules200915666

37. Hung P. Van, Hatcher DW, Barker W. Phenolic acid composition of sprouted wheats by ultra-performance liquid chromatography (UPLC) and their antioxidant activities. Food Chem. (2011) 126:1896-901. doi: 10.1016/j.foodchem.2010.12.015

38. Liyana-Pathirana CM, Shahidi F. Importance of insoluble-bound phenolics to antioxidant properties of wheat. J Agric Food Chem. (2006) 54:1256-64. doi: 10.1021/jf052556h

39. Farrell TL, Dew TP, Poquet L, Hanson P. Williamson G. Absorption and metabolism of chlorogenic acids in cultured gastric epithelial monolayers? ABSTRACT : drug. Metab Dispos. (2011) 39:2338-46. doi: 10.1124/dmd.111.040147

40. Farah A. dePaula Lima J. Consumption of Chlorogenic Acids through Coffee and Health Implications. Beverages. (2019) 5:11. doi: 10.3390/beverages5010011

41. Lafay S, Gil-Izquierdo A, Manach C, Morand C, Besson C, Scalbert A. Chlorogenic acid is absorbed in its intact form in the stomach of rats. J Nutr. (2006) 136:1192-7. doi: 10.1093/jn/136. 5.1192

42. Manach C, Rémésy C, Scalbert A, Jiménez L, Morand C. Polyphenols: food sources and bioavailability. Am J Clin Nutr. (2004) 79:727-47. doi: $10.1093 / \mathrm{ajcn} / 79.5 .727$
43. Williamson G, Clifford MN. Colonic metabolites of berry polyphenols: the missing link to biological activity? Br J Nutr. (2010) 104:48-66. doi: 10.1017/S0007114510003946

44. Nørskov NP, Hedemann MS, Theil PK, Fomsgaard IS, Laursen BB, Knudsen KEB. Phenolic acids from wheat show different absorption profiles in plasma: A model experiment with catheterized pigs. J Agric Food Chem. (2013) 61:8842-50. doi: 10.1021/jf4002044

45. Ludwig IA, Paz de. Peña M, Concepción C, Alan C. Catabolism of coffee chlorogenic acids by human colonic microbiota. BioFactors. (2013) 39:623-32. doi: 10.1002/biof.1124

46. Rechner AR, Smith MA, Kuhnle G, Gibson GR, Debnam ES, Srai SKS, et al. Colonic metabolism of dietary polyphenols: Influence of structure on microbial fermentation products. Free Radic Biol Med. (2004) 36:212-25. doi: 10.1016/j.freeradbiomed.2003.09.022

47. Breynaert A, Bosscher D, Kahnt A, Claeys M, Cos P, Pieters L, et al. Development and validation of an in vitro experimental gastrointestinal dialysis model with colon phase to study the availability and colonic metabolisation of polyphenolic compounds. Planta Med. (2015) 81:1075-83. doi: 10.1055/s-0035-1546154

48. Scalbert A, Williamson G. Bioavailability of Polyphenols. J Nutr. (2000) 2073-85. doi: 10.1093/jn/130.8.2073S

49. Mosele JI, Macià A, Motilva MJ. Metabolic and microbial modulation of the large intestine ecosystem by non-absorbed diet phenolic compounds: A review. Molecules. (2015) 20:17429-68. doi: 10.3390/molecules200917429

50. Velderrain-Rodríguez GR, Palafox-Carlos H, Wall-Medrano A, Ayala-Zavala JF, Chen CYO, Robles-Sánchez M, et al. Phenolic compounds: their journey after intake. Food Funct. (2014) 5:189-97. doi: 10.1039/C3FO60361J

51. Lindenmeier M, Faist V, Hofmann T. Structural and functional characterization of pronyl-lysine, a novel protein modification in bread crust melanoidins showing in vitro antioxidative and phase I/II enzyme modulating activity. J Agric Food Chem. (2002) 50:6997-7006. doi: 10.1021/jf020618n

52. Guzman-Rodriguez M, McDonald JAK, Hyde R, Allen-Vercoe E, Claud EC, Sheth PM, et al. Using bioreactors to study the effects of drugs on the human microbiota. Methods. (2018) 149:31-41. doi: 10.1016/j.ymeth.2018.08.003

53. Mithul Aravind S, Wichienchot S, Tsao R, Ramakrishnan S, Chakkaravarthi S. Role of dietary polyphenols on gut microbiota, their metabolites and health benefits. Food Res Int. (2021) 142:110189. doi: 10.1016/j.foodres.2021.110189

54. Jiménez-Zamora A, Pastoriza S, Rufián-Henares JA. Revalorization of coffee by-products. Prebiotic, antimicrobial and antioxidant properties. LWT - Food Sci Technol. (2015) 61:12-8. doi: 10.1016/j.lwt.2014.11.031

55. Silván JM, Morales FJ, Saura-Calixto F. Conceptual study on maillardized dietary fiber in coffee. J Agric Food Chem. (2010) 58:12244-9. doi: $10.1021 /$ jf102489u

56. Zhang B, Zhang Y, Li H, Deng Z, Tsao R, A. review on insoluble-bound phenolics in plant-based food matrix and their contribution to human health with future perspectives. Trends Food Sci Technol. (2020) 105:347-62. doi: 10.1016/j.tifs.2020.09.029

57. Acosta-Estrada BA, Gutiérrez-Uribe JA, Serna-Saldívar SO. Bound phenolics in foods, a review. Food Chem. (2014) 152:46-55. doi: 10.1016/j.foodchem.2013.11.093

Conflict of Interest: The authors declare that the research was conducted in the absence of any commercial or financial relationships that could be construed as a potential conflict of interest.

Publisher's Note: All claims expressed in this article are solely those of the authors and do not necessarily represent those of their affiliated organizations, or those of the publisher, the editors and the reviewers. Any product that may be evaluated in this article, or claim that may be made by its manufacturer, is not guaranteed or endorsed by the publisher.

Copyright (C) 2021 Alves, Lobo, Domingues, Monteiro and Perrone. This is an openaccess article distributed under the terms of the Creative Commons Attribution License (CC BY). The use, distribution or reproduction in other forums is permitted, provided the original author(s) and the copyright owner(s) are credited and that the original publication in this journal is cited, in accordance with accepted academic practice. No use, distribution or reproduction is permitted which does not comply with these terms. 